\section{Delving into the ancient brain}

\author{
On Deep History and the Brain \\ by Daniel Lord Smail \\ University of California Press: 2007. \\ 286 pp. \$21.95, £12.95 \\ The Origins of Meaning: Language in the \\ Light of Evolution \\ by James R. Hurford \\ Oxford University Press: 2007. 404 pp. \\ $\$ 35$
}

\section{Dean Falk}

On Deep History and the Brain and The Origins of Meaning are both concerned to some degree with the evolution of human behaviour and the brain, but their similarity stops there. Historian Daniel Lord Smail takes on the full chronology of the human past and condenses it into a seamless narrative; James R. Hurford, a linguist, delves even further into the past to explore the evolutionary foundations of language.

Smail believes that history should bring prehistory into its fold, and focuses on biology, brain and behaviour in his endeavour. $\mathrm{He}$ first describes how the discovery and implications of deep time by geologists, biologists and naturalists in the mid-nineteenth century were the undoing of the sacred idea that humankind began relatively recently in the Garden of Eden. Historians then shifted from a sacred to a secular beginning - the rise of civilization in Mesopotamia. Thus, laments Smail, the Palaeolithic continued to receive short shrift and still needed to be 'historicized.' After all, humans who did not keep records still had a past. He has a point.

Smail examines the rupture that continues to separate prehistory from recorded history, together with the historiographical, epistemological and theoretical obstacles that have kept them apart. He explores the importance of biology in shaping cultural evolution, offering an interesting take on the nature/nurture dichotomy with his suggestion that lamarckian mechanisms displaced darwinian ones when human culture started to develop.

Smail's discussion of the brain is framed within a critique of evolutionary psychology, which considers that cognitive modules have been handed down, more-or-less unchanged from the deep evolutionary past - "Stone Age brains acting clumsily in modern environments." Cognition has been overemphasized, he believes, to the detriment of the drives, motivations, emotions, moods and other neurophysiological states that are important for shaping human mental experiences.

The contention here is that certain cultural practices affecting brain-body chemistry through psychotropic mechanisms are amenable to a neurohistorical approach. Palaeolithic societies, for example, may have developed a range of mood-altering practices such as song, dance, ritual, and ingestion of mind-enhancing substances. Fast-forward to eighteenth-century Europe, when these were joined by caffeine, sentimental novels, pornography and a growing array of consumer goods. Today we have shopping, drugs and gossip.

Psychotropic practices have been used in the past by authoritarian institutions or governments to control people. Smail suggests that they arose slowly during the later Palaeolithic, accelerated in the Neolithic, and soared during the past few centuries; he attributes our enjoyment of them to the fact that we are social creatures who have always assessed our standing in groups through chemical cues. Perhaps so.

Although this is an enjoyable and creative book, it is not quite what I expected. There are no endocasts or sulcal patterns here, no Brodmann's area 10, or debates on brain size versus cortical reorganization (although Hobbits receive a brief mention). Notwithstanding these omissions, its fla-

vour and neurohistorical

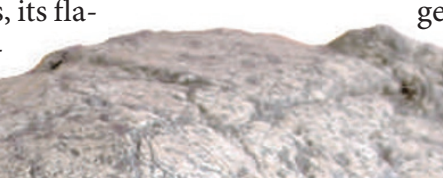

approach are original and provocative, and the suggestion rings true that the neurophysiological underpinnings of moods, motivations, and so on, were important during hominin cultural and neurological evolution.

Hurford's book, The Origins of Meaning, also addresses an interdisciplinary audience, extending to philosophers, psychologists, anthropologists, cognitive scientists and ethologists. The topic of language origins is an intellectual minefield, and those who tread on it need good balance - which Hurford has. Language, he neatly observes, allows humans to "go public with their thoughts".

A large part of the book reviews the experimental literature on the cognition of animals to model the protolinguistic substrates that probably characterized our earliest hominin ancestors. The late African grey parrot Alex, the famous vervet monkeys, and the chimpanzees Kanzi, Austin and Sherman are all here. So are a host of anonymous animals, such as bright piglets that back out of the 'wrong' arms of Tmazes, apparently to avoid giving incorrect responses. Do animals know what they know — that is, do they have self-awareness? Hurford shows that the seeds are there, and were probably present in our ancestors, providing fodder for natural selection.

Likewise, the capacity to realize something about objects (even that they are no longer present) is common to many animals and may have been a prerequisite for the emergence of the linguistic feature of 'displaced reference. Hurford argues that the ability of many animals to infer animacy in objects (related to detecting biological motion) was necessary for our ancestors to evolve 'theory of mind'. Other comparative discussions include the evolution of episodic memory, which Hurford thinks emerged more recently than semantic memory, and the accurate perception of a number of objects without counting (usually around four), and the relationship of such abilities to the evolution of specific aspects of language.

Hurford locates an evolutionary starting point for language in early hominins in the simple two-way communications from which grammatical complexity and descriptive power eventually grew. He discusses physical and social environments of apes to locate possible precursors of group-wide reciprocal communications. He rejects male-female relationships and parent-offspring interactions because they are too asymmetrical, but views play behaviour among juveniles as more symmetrical and therefore a likely precursor. The literature on
Cranium of Tournaï, the earliest known hominid. Will we ever know what went on inside it? 
mother-infant interactions, however, indicates that these are not asymmetrical and may have been a focus of intense natural selection.

The discussions in The Origins of Meaning of ritualization, emulation, imitation, learning and 'machiavellian intelligence' are insightful. So is the review of communications that include gaze-following, attention-seeking behaviour, pointing, begging and alarm calls in nonhuman primates and/or young humans, and their possible implications for the evolution of referential language. After considering niche construction, kin and sexual selection, and reciprocal altruism, Hurford concludes that communicative cooperation and trust may have been the most crucial factors in the emergence of language.

There are some titillating nuggets in this book, such as a discussion of how the FOXP2 gene was mistakenly accepted as the 'magic bullet' responsible for language evolution. Even better is the extent to which academics from different countries use language competitively to show off - guess where Americans rank?

Has Hurford achieved his goal of describing the evolutionary foundations of language? Yes, elegantly and in accomplished detail that should be accessible to all those specialists the book targets. I look forward to finding out what he thinks happened next in the second volume.

Dean Falk is in the Department of Anthropology, Florida State University, Tallahassee, Florida 32306-7772, USA. She is the author of Braindance: New Discoveries about Human Origins and Brain Evolution.

\section{Space and time gift-wrapped}

\author{
Very Special Relativity: An illustrated \\ Guide \\ by Sander Bais \\ Harvard University Press: 2007. 144 pp. \\ $\$ 20.95, \notin 13.95$
}

\section{Andrew Jaffe}

Sander Bais's Very Special Relativity is a brief overview of Albert Einstein's 1905 theory of space and time, an esoteric topic that one would presume to be directed at a narrow audience. But this book would not be out of place on a coffee table, with its handsome design, thick, coloured papers and imaginative graphics that match the high standard of its content. We expect art books, not science texts, on our coffee tables, assuming that in science it is the ideas that matter, not the visual presentation.

Here, the elegant illustrations help Bais lead the reader from Einstein's postulates through the ideas of simultaneity, inertial frames, time dilation and relativistic energy and momentum, eschewing the usual admonitions against equations. The author's clever idea of pairing every page of text with a space-time diagram (a graphical tool actually used by relativists) to illustrate the concepts and mathematics suits the geometrical basis of its subject perfectly. It allows Bais to stop just short of using calculus - although the definitions of things such as 'slope' and 'tangent' are taken for granted, and he does allow a $\mathrm{d} p / \mathrm{d} t$ to slip in when discussing momentum and forces. He manages to navigate all the way to $E=m c^{2}$ and to give us a taste of Einstein's even more miraculous work of the following decade, his general relativity theory of gravitation.

Very Special Relativity is aimed at an underserved market: keen high-school students will welcome it because it extends beyond qualitative discussion of 'modern' physics and popular-science books. With its brainteaser problems, it should also work as an undergraduate introductory textbook. Readers who haven't exercised their mathematical and geometric muscle since they were in school might find it tough going.

It is rare for science books to rate as objects in their own right, but Very Special Relativity is a lovely little object. You could easily imagine a web-based version of it, with a bit of animation to serve its pedagogical needs. Still, there is some quality about the hard covers and high resolution that even my 26 -inch screen wouldn't be able to capture. No longer is there an excuse for physics textbooks to be expensive, boring, thick or stuffed with equations in order to qualify as good teaching material. Andrew Jaffe is professor of astrophysics and cosmology in the Astrophysics Group, Blackett Laboratory, Imperial College London, London SW7 2AZ, UK.

\section{PAINTING}

\section{Hidden depths spotted}

Emiliano Feresin

Nuclear physicists have revealed that the work of Sicilian artist Antonello da Messina (1430-79) may have been ahead of its time. He was among the first, they suggest, to subtly refine the shading in his paintings by spotting them with lacquer. When applied to particular areas of a painting, this glaze, made from red pigment mixed with oil, enhances the impression of depth.

Pier Andrea Mandò and his colleagues at the Italian National Institute of Nuclear Physics' Labec laboratory in Florence took advantage of the availability of Antonello's Portrait of a Man (1476) during its restoration this summer. They had already developed and used non-destructive PIXE (for 'particleinduced X-ray emission') scans to reconstruct the spatial distribution and concentration of chemical elements on the surface of some types of artistic work, such as gold laces and embroideries. They wanted to try the technique for the first time on a painting.

The physicists identified traces of aluminium and iron - a typical signature of lacquers in tiny, uneven spots over the red cloak of the unknown subject. Although such glazes were already in use in the fifteenth century, they were normally applied with a brush over an entire surface. The scan reveals a weave-like imprint across the red cloak, suggesting to the restorers that here the shiny substance was dabbed on with a cloth.

Later, similar effects were created by great masters such as Leonardo da Vinci (14521519), who used his finger, and Rembrandt (1606-69), who used the end of his brush. But if Mandò and his colleagues are correct, it was Antonello - best known for introducing certain techniques of Flemish masters into Italy - who pioneered the effect. Emiliano Feresin is an intern in Nature's Munich office.

The restored Portrait of a Man, pictured here, can be viewed at the Civic Museum of Ancient Art in Palazzo Madama, Turin: www.palazzomadamatorino.it.

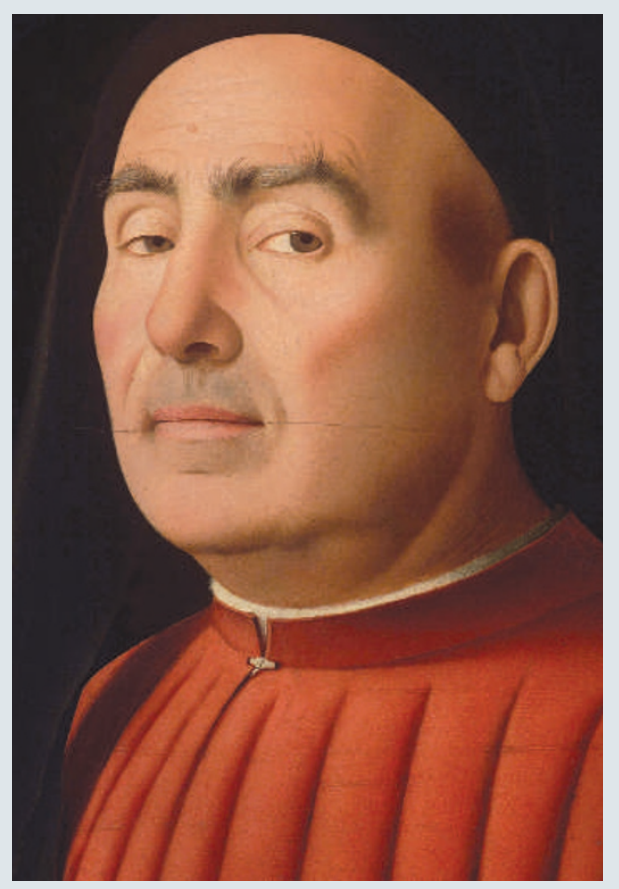

